\title{
Contamination of Heavy Metals (Lead, Zinc, Magnesium and Manganese) Concentrations in Human Eyes
}

\author{
Nazar S. Haddad ${ }^{1}$, Salah Z. Alasadi ${ }^{2}$, Hanaa H. Haddad ${ }^{3}$ \\ ${ }^{1}$ Pathalogy Department of Biochemistry, College of Science, University of Basra, Basra, Iraq \\ ${ }^{2}$ College of Science, University of Basra, Basra, Iraq \\ ${ }^{3}$ Chemistry Department, College of Science, University of Basra, Basra, Iraq \\ Email: hanaa_hadadd@yahoo.com
}

Received May 9, 2012; revised June 13, 2012; accepted June 23, 2012

\begin{abstract}
The aim of our study is to measure the concentration of lead, zinc, magnesium and manganese, toxic/transition metals in human lens. The analyzed samples were categorized according to their personal habits (smoking, food, drinking and medical history). Demographic and laboratory characteristics of patients, the patients were twenty six males and twenty females. The comparison of trace elements between patients and control revealed significant increase of lead and manganese levels in patients and significant decrease of magnesium while there was few significant difference in zinc concentration among them.
\end{abstract}

Keywords: Heavy Metals; Human Eyes; Atomic Absorption

\section{Introduction}

Contamination of the environment refers to the dispersion of chemical substances from localized sources into worldwide distribution in the environment caused by human activities [1]. Lead contamination is widespread in our environment primary due to leaded petroleum and lead-based paint causing practically every adult to have amassed some degree of lead in their system [2]. In industrial settings avoiding lead exposure of pregnant woman, children is particularly crucial [3]. Eye protection such as splash and impact resistant goggles as well as face shields is also necessary [4]. It is advised that contact lenses should not be worn when working with tetraethyl lead. Chronic exposure to metals at high enough level to cause chronic toxicity effects [5], such as hypertension in individuals exposed to lead can also occur in individuals who have no symptoms.

Low level metals exposure contributes much more towards the causation of chronic disease and impaired functioning than previously thought [6]. Essential trace elements such as zinc and copper participate in various enzymatic reactions directly related to the regulation of blood pressure, the toxicological action of several heavy metal ion such as lead can cause hypertension by effecting hormone metabolism [7]. Magnesium may be important in physiological regulation of blood pressure whereas alteration in cellular magnesium metabolism could contribute to the pathogenesis of blood pressure elevation
[8]. Nutritional toxicological and genetic research over the past century has led to the recognition of the critical role micronutrients/transition metals such as $(\mathrm{Mn}, \mathrm{Cu}$ and $\mathrm{Zn)}$ play in diverse cellular and molecular events. The characterization of various metal-binding and transport protein revealed their role in intracellular absorption, transition and storage of metals and their role in disease pathology [9].

\section{Materials and Methods}

\subsection{Apparatus}

Ashimadzu atomic absorption spectrophotometer model (AA-630-12) was used with an air-acetylene burner (slot dimensions $100 \times 0.62 \mathrm{~mm})$. Instrument settings were: lamp current, $10 \mathrm{~mA}$; wave length, $285.2 \mathrm{~nm}$; slit width, $0.2 \mathrm{~nm}$. These conditions were maintained constant throughout the measurements.

\subsection{Reagents}

Metals stock solutions: add $200 \mathrm{mg}$ of metals to a $100 \mathrm{ml}$ volumetric flask. Dissolve using the minimal quantity of hydrochloric acid. Dilute to volume with deionized water.

Metals working standards: Transfer $0.5-5 \mathrm{ml}$ of the stock solution to ten a $100 \mathrm{ml}$ volumetric flask and dilute to volume with deionized water. This gives a concentrations of $10-100 \mu \mathrm{g} \mathrm{Metal} / \mathrm{ml}$. 


\subsection{Preparation of Samples}

Each lens was placed into pre weight digestion tube. The sample was weighted to determine a dry weight (gram) after drying at $95^{\circ} \mathrm{C}$ overnight [10]. Next day reweighted to determine dry weight $(\mathrm{gm})$, then $(1 \mathrm{ml})$ of concentrated nitric acid was added digest tube which was placed in waterbath at $100^{\circ} \mathrm{C}$, the sample digested for approximately $1 \mathrm{~h}$ until all tissues material has been dissolved, then $(1 \mathrm{ml})$ perchloric acid was added until (deep brown color) with clear solution was obtain dilute each sample to mark with deionized water to $10 \mathrm{ml}$.

\subsection{Statistical Analysis}

The statistical analysis were carried out using two-way analysis of variance with unbalanced repeated measurements. Statistical significance between individual time points was made by using Revised Least Significant Difference (RLSD) test. The probability level for significance was $5 \%$ less.

\section{Results and Discussion}

As a result of human activities, lead and its compounds can be found in all parts of our environment this includes air and water [9], it is accumulative with age in bones, aorta, kidney and liver. Lead is a general protoplasmic poison that is cumulative, slow acting and subtle and produces a variety of symptoms. Essential trace elements play major roles in many metabolic pathways. There are many factors such as cultural habits, socioeconomic status environmental exposure and diet may have contribution to the trace metals in blood stream of humans and ultimately cause some disease/health impact [11]. Average concentration of lead in flutestripped cigarette is 2.4 $\mu \mathrm{g} / \mathrm{g}$ about $6 \%$ passing into main steam smoke [12], therefore smoker and former smokers have higher blood lead levels than non-smokers. Cigarettes consumption depress the activity of enzyme 5-aminolevolinic acid dehydratase (most sensitive indicator of the lead burden to the body) in erythrocytes from 117.5 activity units in non-smoker to 88.8 in smokers of less than 20 cigarettes/ day to 74.1 in heavy smokers of more than 20 cigarettes/ day [13].

Zinc is a vital mineral in eye health. A deficiency has been linked to retinal detachment, it is a factor in metabolic functioning of several enzymes in the choriortinal complex (the vascular coating of the eye). It may also protect against light-induced damage and deficiency has been linked to molecular degeneration [14]. Copper and manganese are important for proper healing and for retarding the growth of cataracts [15].

In this study heavy metals (lead, zinc, magnesium and manganese) concentrations in human eyes. Table 1 shows their characters. All the measurements of the eyes sam-
Table 1. Study groups characters.

\begin{tabular}{lc}
\hline Study groups & Character \\
\hline Total & 46 \\
Male & 26 \\
Female & 20 \\
Outskitrs & 29 \\
City centre & 17 \\
Smoker & 20 \\
Non-smoker & 26 \\
& Associated diseases \\
Hypertension & 7 \\
Diabetes mellitus & 5 \\
Bacterial infection & 10 \\
& \\
Mantol fluide & 3 \\
Cidamex & Drugs \\
Optiflox drop & 4 \\
Fucithalmic oint & 3 \\
Betacol drop & 5 \\
Samaphinicol oint & 1 \\
\hline
\end{tabular}

ples subjected to statistical analysis using the independent samples RLSD-test to compare between measurements of the study groups (smoker and none-smoker), sex (males and females), life environment (outskirts and citycentre) and (patients and control) groups.

The statistic results showed that there is a significant difference $(\mathrm{p}<0.001)$ in the metal levels in all the compared males and females eyes measurements as shown in Figure 1, the concentration of the four metals in eyes about $20 \%$ excess in females higher than in males. From this findings it would appear that while variation does occur in concentrations of metals in eyes with difference in sex, no definite pattern of distribution is present.

Figure 2 illustrates the variation in the concentration of metals in human eyes as a function of life environments. Statistically significant differences $(p<0.001)$ were observed between persons living in city centre and others who living in outskirt for concentrations of all three metals. Geographical influences are thought to be the main source of variability. The observed variations are probably a reflection of the varying levels present in foods, that are generally dependent on geochemical environment in which they are living. Environmental contamination can also be a source of metals a human eyes. Figure 3 illustrates that there is a statistical relationship between the metals levels in eyes of smoker and nonsmoker groups. The concentration of metals in the smokers persons was about $50 \%$ higher than in the non-smoker persons. 


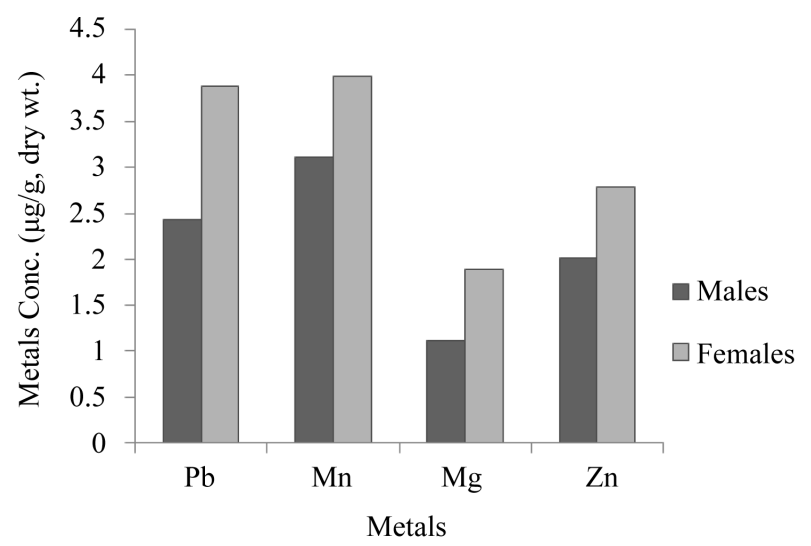

Figure 1. Concentrations of metals in human eyes as a function of sexes.

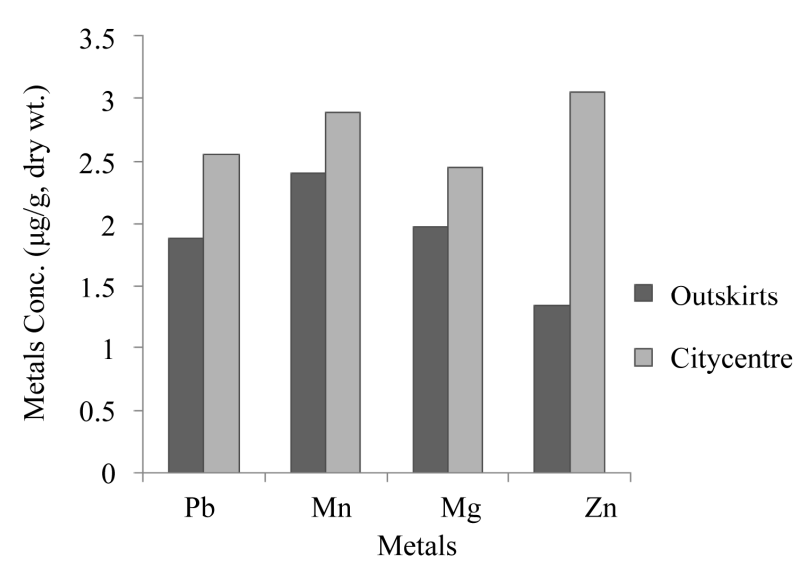

Figure 2. Concentrations of metals in human eyes as a function of life environment.

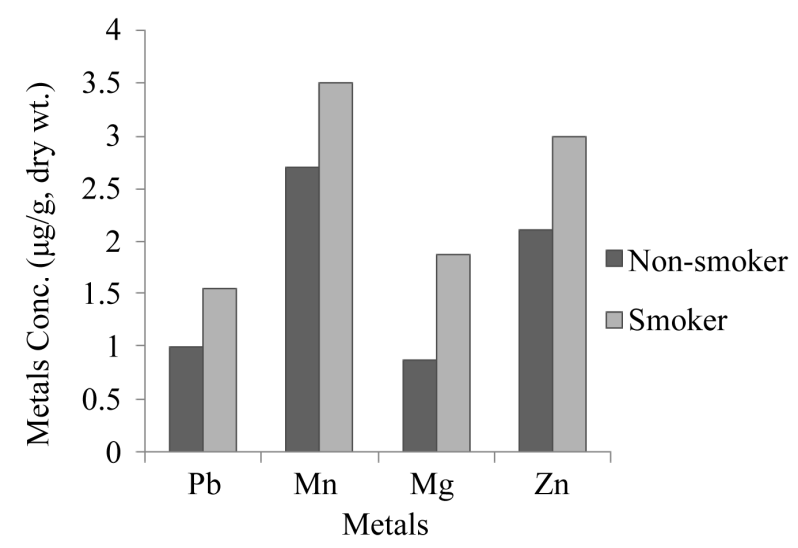

Figure 3. Concentrations of metals in human eyes as a function of health case.

As shown in Figures 4-6, there was a statistical relationship between the metals levels in human eyes of patients and control groups $(\mathrm{p}<0.01)$. The concentration of metals in patients eyes was about $40 \%$ lower than in the control group eyes with exception of lead for all type of disease.

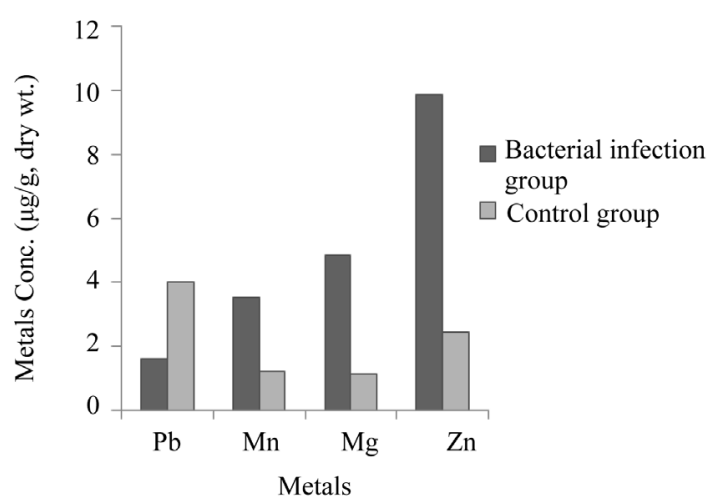

Figure 4. Concentrations of metals in human eyes as a function of health cases.

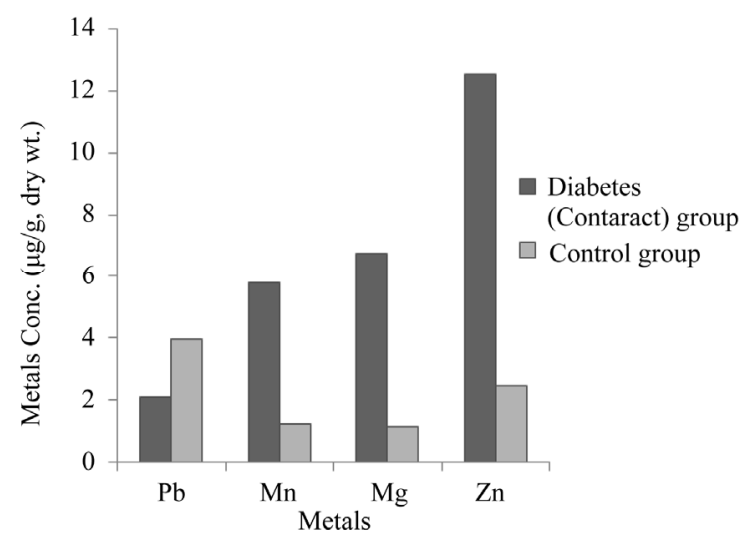

Figure 5. Concentrations of metals in human eyes as a function of health cases.

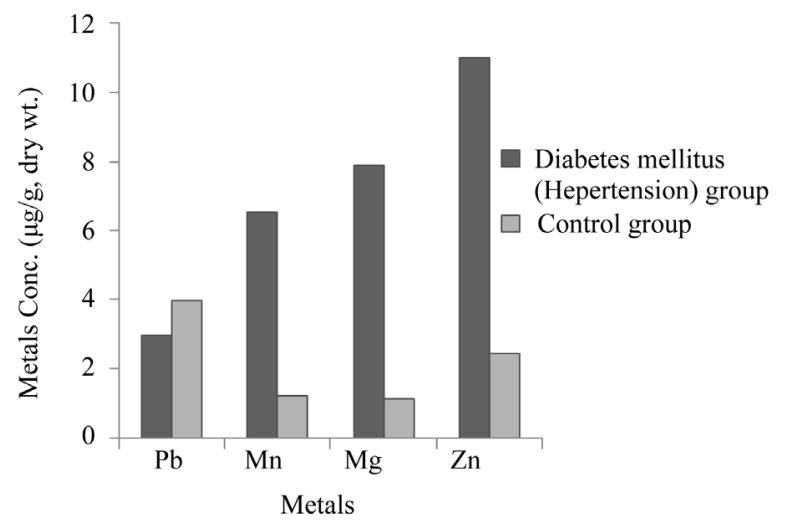

Figure 6. Concentrations of metals in human eyes as a function of health cases.

\section{Conclusions}

Significant relation was observed between samples containing $\mathrm{Pb}, \mathrm{Mn}, \mathrm{Mg}$ and $\mathrm{Zn}$ mentally stress subjects.

1) Clinically high lead encephalopathy in smoker with high exposure to lead [16];

2) The neurological disorder known a manganese results from occupational exposure to manganese dust and 
fumes [17];

3) Significant defer in zinc and magnesium levels in workers suffering from respiratory trouble were significantly high.

Trace/toxic elements play a vital role in human health yet there is obviously a great deal of concern about the obtimum intake and the safe range of each element [18].

\section{Acknowledgements}

Authors wish to thank Dr. S. Z. Alasadi and Z. A. AlAshoor, Ophthalmologist Department, College of Medicine, University of Basra, for their available co-operating in collection of the samples.

\section{REFERENCES}

[1] US Environmental Protection Agency, "Air Quality Criteria for Lead," Environmental Criteria and Assessment Office Annual Report, Jun-EPA-600, Washington DC, 1986, pp. 28-83.

[2] K. R. Mahaffy, "Environmental Lead Toxicity: Nutrition as a Component of Intervention," Environmental Health Perspectives, Vol. 89, 1990, pp. 75-78.

[3] Agency for Toxic Substances and Disease Rigistring (2008), Fex Faqs Retrieved March (2009) from http://www.atsdr.cdc.gov/tox.faq.html

[4] http://www.lenntech.com/periodic-chart-elements/Ba-enhtml

[5] M. Hu, M. Rabinowitz and D. Smith, "Bone Lead as Biological Marker in Epidiomologic Studies of Chronic Toxicity," Environmental Health Perspectives, Vol. 106, 1998, pp. 1-7. doi:10.1289/ehp.981061

[6] R. Kim, A. Rotnitzky and D. Sparrow, "A Longitudinal Study of Low-Level Lead Exposure and Impairment of Renal Function," The Journal of the American Medical Association, Vol. 275, No. 15, 1996, pp. 1177-1181.

[7] E. K. Silbergeld, "Lead in Bones: Implication for Toxicology during Pregnancy and Lactation," Environmental Health Perspectives, Vol. 91, 1991, pp. 63-90.
[8] A. M. Polts and P. C. Au, "The Affinity of Melanin for Inorganic Ions," Experimental Eye Research, Vol. 22, No. 5, 1976, pp. 487-491. doi:10.1016/0014-4835(76)90186-X

[9] A. B. Santamaria, "Manganese Exposure Essentially and Toxicity," Indian Journal of Medical Research, Vol. 128, No. 4, 2008, pp. 484-500.

[10] A. Pompello, A. Visvikis, A. Paolicchi and V. Detata, "The Changing Faces of Glutathione, a Cellular Potogonist," Biochemical Pharmacology, Vol. 66, No. 8, 2003, pp. 1499-1503. doi:10.1016/S0006-2952(03)00504-5

[11] D. Kromhout, "Trace Metals and Coronary Heart Disease Risk Indicator in 152 Elderly Men (the Zutphen Study)," American Journal of Epidemiology, Vol. 122, No. 3, 1985, pp. 378-385.

[12] R. A. Nadkarni, "Investigation on the Relative Transference of Trace Elements from Cigarette Tobacco into Smoke Condensate," Tobacco, Vol. 170, 1970, pp. 25-27.

[13] M. R. Mussalo, "Cigarettes as a Source of Some Trace and Heavy Metals and Pesticides in Man," Archives Environmental Health, Vol. 41, No. 1, 1986, pp. 49-55. doi:10.1080/00039896.1986.9935765

[14] M. Wilhelm and D. Hafiner, "Monitoring of Cadmium, Copper, Lead and Zinc Status in Young Children Using Toenails: Comparison with Scalp Hair," Science of the Total Environment, Vol. 103, No. 2-3, 1991, pp. 199-207. doi:10.1016/0048-9697(91)90145-5

[15] R. Mehra and M. Junejam, “Atomic Absorption Spectrophotometry Determination of $\mathrm{Cd}, \mathrm{Pb}, \mathrm{Cu}, \mathrm{Cr}, \mathrm{Ni}$ and $\mathrm{Fe}$ Levels in Human Hair. Influence of Age Hair Color and Smoking Habit," Journal of the Indian Chemical Society, Vol. 81, No. 4, 2003, pp. 349-350.

[16] R. Nath, "Health and Disease, Role of Micronutrients and Trace Elements," APH Publishing Corporation, New Delhi, 2000.

[17] A. Bell, "Traking Down the Cause of Mysterious Illness," ECOS Magazine, Vol. 57, 2000, pp. 3-8.

[18] R. Mehra and M. Juneja, "Adverse Health Effects in Workers Exposed to Trace/Toxic Metals at Workplace," Indian Journal of Biochemistry \& Biophysics, Vol. 40, No. 2, 2003, pp. 131-135. 